\title{
ONTOLOGIA E MÉTODO NO PENSAMENTO DO ÚLTIMO LUKÁCS
}

Title: ontology and method in the last thought Lukács

Hidemi Soares Miyamoto ${ }^{1}$

RESUMO: O objetivo deste texto é realizar uma análise da reinterpretação da teoria social de Marx empreendido pelo pensador húngaro György Lukács. Pretendemos analisar de que forma Lukács interpreta as questões atinentes à ontologia, à metodologia e à epistemologia no pensamento de Marx. Tentamos compreender como estes três elementos se encontram articulados especialmente nas obras póstumas Prolegômenos para uma ontologia do ser social (2010), Para uma ontologia do ser social I (2012) e Para uma ontologia do ser social II (2013). Assim como buscamos recuperar a relação existente entre o trabalho e o conhecimento humano no pensamento crítico de Lukács e Marx.

PALAVRAS-CHAVES: Ontologia; Trabalho; Dialética.

ABSTRACT: The objective of this paper is to analyze the reinterpretation of the social theory of Marx undertaken by the hungarian thinker György Lukács. We intend to analyze how Lukacs interprets questions concerning the ontology, the methodology and the epistemology in Marx's thought. We try to understand how these three elements are articulated especially in the posthumous works Prolegômenos para uma ontologia do ser social (2010) Para uma ontologia do ser social I (2012) and Para uma ontologia do ser social II (2013). As we seek to recover the relationship between labor and human knowledge in Marx's and Lukacs's the critical thinking.

KEYWORDS: Ontology; Labor; Dialectic.

\section{INTRODUÇÃO ${ }^{2}$}

Neste presente artigo buscaremos analisar a contribuição da última fase do pensamento de György Lukács (1881-1971), notadamente o período em que o autor se centra em discussões referentes à ontologia e, sua subsequente crítica ao pensamento que se orienta tão somente através de pressupostos lógicos ou gnosiológicos. Com efeito, Lukács enfatiza que,

\footnotetext{
${ }^{1}$ Mestre em Ciências Sociais pela Universidade Federal da Bahia (UFBA)e doutorando também em Ciências Sociais pela UFBA.

${ }^{2}$ Devo agradecer imensamente a Bruno Evangelista por sua atenção e gentileza em realizar correções ao texto.
} 
Certamente ninguém se surpreenderá - menos ainda o autor destas linhas - ao constatar que a tentativa de basear o pensamento filosófico do mundo sobre o ser se depara com resistências de muitos lados. Os últimos séculos do pensamento filosóficos foram dominados pela teoria do conhecimento, pela lógica e pala metodologia, e esse domínio está longe de ser superado. (LUKÁCS, 2010, p. 1).

Para tanto, centraremos nossa discussão tendo como base três obras póstumas ${ }^{1}$ de Lukács: Prolegômenos Para uma Ontologia do Ser Social (2010), Para uma Ontologia do Ser Social I (2012) e Para uma Ontologia do Ser Social II (2013).

A escolha desse autor se justifica por nos parecer a abordagem mais instigante e, de nosso ponto de vista a mais correta também, da teoria social de Marx, pois recupera uma discussão de cunho ontológico que ficou, na visão do autor, escamoteada no desenvolvimento do pensamento marxista ao longo do século XX. O pensamento ontológico de Lukács, apoia-se especialmente, em uma conhecida passagem em Marx dos Grundrisse (2011), segundo o qual "as categorias expressam formas de ser, determinações de existência” (MARX, 2011, pg.59), apontando, desse modo, para a dimensão ontológica do pensamento de Marx. Tais categorias exprimem a própria realidade apresentada de forma conceitual, isto é, o chamado "concreto pensado", a realidade efetiva, para a qual a ontologia tornar-se-ia o fundamento do método marxiano.

\section{MÉTODO E ONTOLOGIA.}

O argumento modal de Lukács é de que haveria certa unidade referente a metodologia, a teoria do conhecimento e a ontologia, tanto na dialética hegeliana, como - a grosso modo - na de Marx, porém o método e a gnosiologia estariam subordinados às características da própria realidade efetiva. Nesse sentido, um dos diferenciais entre a dialética de Hegel e Marx estaria na introdução levada a cabo por Marx do conceito de "momento predominante", além da conhecida inversão materialista, que caberia à própria realidade, ou seja, a ontologia.

Esse "momento predominante" teria possibilitado para Marx superar o arranjo estacionário que haveria na dialética de Hegel, pois na interrelação entre os diversos elementos que compõem uma dada totalidade, se não houvesse esse "momento predominante" -, ou seja, um elemento da própria realidade que direciona o desenvolvimento de um objeto ao automovimento de todo ser -, em última instância, seria um não-movimento. Pois, segundo o

\footnotetext{
${ }^{1}$ Segundo José Paulo Netto na Apresentação à Para uma ontologia do ser social volume I a primeira edição integral da obra data do ano de 1976, portanto, cinco anos após a morte do pensador húngaro.
} 
autor, os elementos contrastantes de um dado ente se anulariam ocasionando uma imobilidade, ao invés de um movimento, Segundo Lessa (2011-12),

\begin{abstract}
Nesta muito resumida exposição, seria uma grave falha se não mencionássemos - ainda que apenas em um parágrafo - que uma das peculiaridades da Ontologia de Lukács no interior do marxismo reside justamente na importância que confere à categoria do momento predominante (übergreifendes Moment). Segundo esta obra, em todo e qualquer processo social atua um momento predominante. A demonstração pelo filósofo húngaro de que em Marx não há qualquer "fim da história", ou qualquer concepção teleológica da evolução humana, também tem na categoria do momento predominante um aspecto central: sem o momento predominante não teria sido possível a Marx expressar no plano teórico a processualidade puramente causal que é a história. As muitas contradições da sua processualidade não conduzem em Marx a um arranjo estacionário (como ocorre, ao final, em Hegel) precisamente porque em cada interação sempre um dos elementos exerce o momento predominante. (LESSA, 2011$12, \mathrm{p} .8)$.
\end{abstract}

Devemos salientar que dentro do percurso intelectual do próprio Lukács trata-se de uma mudança substancial em seu entendimento da teoria marxiana a discussão sobre ontologia. Em seu ensaio, O que é o marxismo ortodoxo? $(1920)^{1}$ o autor afirma que a ortodoxia do marxismo se referiria tão somente ao método, pois, para ele Marx teria encontrado o método correto de apreensão da realidade. Nesse caso,

O marxismo ortodoxo não significa, pois, uma adesão sem crítica aos resultados da pesquisa de Marx, não significa uma fé numa ou noutra tese, nem a exegese de um livro sagrado. A ortodoxia em matéria de marxismo refere-se, pelo contrário e exclusivamente ao método. (LUKÁCS, 1974, p. 15).

A prioridade dada ao método que se encontra no pensamento do jovem Lukács cedeu espaço para a prioridade da própria realidade, da ontologia. Nesse sentido, haveria dois inconvenientes nessa postura que se centra nas discussões sobre o método como sendo o critério da verdade científica.

O primeiro ponto a ser criticado seria o fato de que haveria um deslocamento no critério de validade na ciência. Em vez da própria realidade ser o fundamento último de correção ou incorreção de uma análise científica, o método seria esse critério, de modo a possibilitar a existência de resultados científicos distintos, mesmo com a utilização de uma única abordagem metodológica. O próprio marxismo seria um exemplo disso, pois comportaria em seu interior interpretações tão díspares como, por exemplo, o marxismo analítico de John Elster (1940) e o estruturalismo-marxista de Louis Althusser (1918-1990), dois exemplos paradigmáticos do campo marxista $^{2}$.

\footnotetext{
${ }^{1}$ Ensaio esse que se encontra na obra que marca sua adesão ao comunismo: História e consciência de classe.

${ }^{2}$ Encontramos uma análise detalhada sobre esse assunto no texto de Sérgio Lessa, Lukács e o Marxismo Contemporâneo (1993).
} 
O segundo momento problemático dessa concepção em relação ao universo teórico de Marx estaria no fato de que a construção da objetividade seria um produto da subjetividade. Então, a realidade seria um mero construto de nosso processo gnosiológico. Sendo assim, a centralidade do método inverteria a relação entre o ser e a consciência, de maneira que não seria mais o ser que determinaria a consciência e sim a consciência que determinaria o ser. Posto desta forma, a própria realidade social aparece em Marx como fundamento último do ser ou do não-ser social de um determinado fenômeno social. E isso independentemente se determinada forma de consciência social é correta ou falsa do ponto de vista ontológico. Essa postura de Marx já se encontra visível em sua análise da crítica lógico-gnosiológica de Kant acerca da existência de Deus.

Para Marx apud Lukács (2012, p.283), mesmo sendo correta a crítica de Kant sobre a inexistência de Deus haveria um aspecto negativo nessa análise kantiana. Pois, trata-se de uma crítica que se restringia ao aspecto lógico-gnosiológico e não levava em consideração a influência dessas construções ideológicas no comportamento efetivos dos homens. Haveria em Marx já naquele período a centralidade da função prática-social de determinadas formas de consciência social.

Portanto, seria característico do pensamento ontológico de Lukács apontar a função social como a esfera resolutiva dos complexos sociais, entre os quais a discussão sobre o método. A esfera lógico-gnosiológica deixa de ser em Lukács, e em Marx, o critério de validade do método científico passando a ser a função social que ele exerce dentro do complexo social. Cada esfera particular da sociedade, política, jurídica, ciência, deveria fornecer respostas às necessidades sociais postas pela reprodução social, e é somente nesse sentido que devemos entender a lógica que a função social adquire no pensamento de Lukács.

O método científico tem fundamentalmente a particularidade de proporcionar um alargamento do conhecimento humano enquanto função social. Dessa forma, buscaria apreender certos fenômenos que ainda são desconhecidos buscando incorporá-los ao que já conhecemos. E, dessa forma, a incorporação de novas determinações do real até então desconhecidas provocaria uma nova relação entre o conhecido e o desconhecido, de modo que o que nós conhecemos e o que desconhecemos seriam dois polos distintos de um mesmo processo social, provocando a busca por descobrirmos os nexos causais que operam na realidade. E vale a pena ressaltar que esse processo de conhecimento da realidade é determinado em última instância pelas necessidades da reprodução social. 
Para Lessa (1999) ${ }^{1}$, uma consequência dessa relação entre o conhecido e desconhecido reside no fato de que do ponto de vista do método não haveria como saber quais seriam os caminhos metodológico adequados para se investigar um objeto em particular. Apareceria, dessa forma, um aparente paradoxo, pois, se não há um método adequado a priori como poderia ser investigado um determinado objeto, sem metodologia? Para se resolver esse paradoxo o conceito de totalidade é central na análise luckasiana, pois se cada esfera da realidade, a natureza inorgânica, a orgânica e o ser social, constitui-se como totalidades distintas, mas interdependentes, os procedimentos inerentes a determinados entes que estão inseridos em um complexo particular compartilham fundamentos metodológicos em comum, possibilitando uma aproximação entre objetos distintos que pertencem a uma mesma esfera ontológica. E é como consequência desse fato que se podem elevar as investigações metodológicas de um objeto particular em direção a uma universalização teórica.

Assim posto, José Chasin, de uma forma bem provocativa, afirma que não existiria um "método" em Marx, pois,

Se por método é entendido uma arrumação operativa, a priori, da subjetividade, consubstanciada por um conjunto normativo de procedimentos, ditos científicos, com os quais o investigador deve levar a cabo seu trabalho, então, não há método em Marx. (CHASIN, 2009, p.389).

Debruçamo-nos sobre o conceito de totalidade e de historicidade, pois serão de extrema importância para entendermos o fundamento ontológico do método em Marx, segundo a interpretação de Lukács. Dessa afirmação se sobressai dois importantes conceitos atinentes ao método dialético: o primeiro conceito seria da centralidade da história na dialética. Todo ser é histórico. Natureza e sociedade formariam dois complexos que são ontologicamente distintos entre si, mas mantendo entre si uma mútua relação. “O jovem Marx já havia reconhecido e dito expressamente que toda sociedade constitui uma totalidade” (LUKÁCS, 2012, pg.304). Tanto Marx quanto Engels expressam isso na Ideologia alemã (2010).

Aliás, nessa concepção das coisas tal como realmente são e tal como são e tal como se
deram, todo profundo problema filosófico é simplesmente dissolvido num fato
empírico, como será mostrado mais claramente adiante. Por exemplo, a importante
questão sobre a relação do homem com a natureza (ou então, como afirma Bruno na
p.110, as "oposições em natureza e história", como se as duas "coisas" fossem
separadas uma da outra, como se o homem não tivesse sempre diante de si uma
natureza histórica e uma história natural. (MARX e ENGELS, 2007, p. 31).

\footnotetext{
${ }^{1}$ LESSA, Sérgio. Lukács, ontologia e método: Em busca de um pesquisador(a) interessado(a). In: Revista Praia
} Vermelha. Rio de Janeiro: vol.1, n.2, 1999, pp. 1-2. 
Dentro dessa unidade da história, Lukács argumenta que existem três esferas ontológicas que são distintas entre si, mas, mantêm uma unidade dialética. A natureza inorgânica ou a esfera da ontologia geral, àquela dos elementos químicos em que inexiste a vida propriamente dita, a natureza orgânica, a esfera biológica, e o ser social que se caracteriza por apresentar uma descontinuidade das esferas orgânicas e inorgânicas, mesmo que essa descontinuidade não significa uma total ruptura, pois o ser social se fundamenta nas duas esferas ontológicas precedentes. E, tal salto ontológico, que possibilitou a passagem da natureza orgânica em Marx se dá pelo trabalho. Segundo, o pensador húngaro,

Portanto, só em Marx o problema adquire o seu justo perfil. Antes de tudo, ele vê com clareza que há uma série de determinações categoriais, sem as quais nenhum ser pode ter seu caráter ontológico concretamente apreendido Por essa razão, a ontologia do ser social pressupõe uma ontologia geral. Porém, essa ontologia não pode ser de novo distorcida em teoria do conhecimento. Não se trata aqui de uma analogia ontológica com a relação entre a teoria do conhecimento geral e os métodos específicos das ciências singulares. Trata-se, ao contrário, do fato de que aquilo que é conhecido numa ontologia geral nada mais é que os fundamentos ontológicos de todo ser [...]. Por conseguinte, a ontologia geral ou, em termos mais concretos, a ontologia da natureza inorgânica como fundamento de todo existente é geral pela seguinte razão: porque não pode haver qualquer existente que não esteja de algum modo fundado na natureza inorgânica. (LUKÁCS, 2012, p.27).

Então, necessariamente se trata de uma unidade na diversidade. Se há um compartilhamento de características que une a natureza inorgânica, a orgânica e o ser social, fica evidente que a natureza inorgânica ou a ontologia geral será o fundamento último de todo o método, valendo ressaltar em sua mais ampla universalidade. A diversidade nessa relação irá se referir às particularidades dos objetos a serem estudados, pois, se há uma unidade nessa relação também é verdade que existem diferenças. Sendo assim, voltamos a já aludida relação entre universalidade e particularidade, isto é, se há procedimentos metodológicos universais, existem também elementos particulares que são peculiares a cada esfera da vida.

Em outras palavras, se é verdade que quanto mais tendente à singularidade for o objeto sob investigação, mais particular e requerido o método requerido, o contrário também é verdadeiro. Ou seja, quanto mais universal o objeto investigado, mais genérica tende a ser a validade dos procedimentos metodológicos empregados. Assim, se é verdade que podemos falar de metodologias específicas a cada uma das esferas do real, também podemos falar de uma reflexão metodológica a mais universal, que trate os procedimentos metodológicos mais universais - os quais, portanto, estarão presentes em todas as investigações a serem realizadas. (LESSA, 2013, p. 6).

Vejamos como essa relação entre ontologia e método aparece na obra de Lukács. Para Lessa $(1995)^{1}$, o fundamento ontológico último, que baliza todo arcabouço metodológico do pensador húngaro é o fato de que todo ente apresentaria um “caráter de complexo" e somente a partir do interior desse complexo, que as categorias podem ser adequadamente compreendidas

\footnotetext{
${ }^{1}$ Idem. Lukács: Método e Ontologia. In: Cadernos de Serviço Social. Recife: v.11, 1995, pp. 2-3
} 
do ponto de vista do método. A totalidade só apresenta esse caráter de complexo por ser uma totalidade histórica, de modo que a historicidade se torna um conceito central também para Lukács. Depreende-se dessa relação entre totalidade e historicidade à relação entre essência e aparência. Se todo "ser" é histórico, tanto a aparência quanto a essência de cada ente serão igualmente históricos.

Então temos na Ontologia luckasiana uma conexão entre a essência e a continuidade histórica, pois ela se diferencia da aparência dos fenômenos ${ }^{1}$ justamente por esse caráter contínuo e histórico. Consequentemente, a relação entre essência e aparência nunca será estática, pois tal relação ocorre de forma processual.

\begin{abstract}
Por enquanto, fixemos este primeiro ponto: para o filósofo húngaro o ser é essencialmente histórico. O desdobramento categorial do ser dá origem a dois momentos distintos, porém intrinsecamente articulados. Um primeiro momento é composto por aqueles elementos que articulam em unidade o processo enquanto tal- o que implica, imediatamente, a existência e ação dos momentos singulares em toda processualidade. Tais elementos marcam a continuidade do processo no interior de seu devir, são a sua essência. O segundo momento é dado por aqueles elementos que distinguem cada instante de todos os outros instantes. Essa esfera fenomênica, todavia, apenas pode vir a ser se articulada aos momentos de continuidade, que fazem dessas características fenomênicas partícipes de um dado processo mais geral. E isso, frisemos, é válido tanto para o ser social como para o ser em geral. (LESSA, 2012, p. 50).
\end{abstract}

\title{
MÉTODO ONTOLÓGICO-GENÉTICO EM LUKÁCS
}

Adentremos agora na análise sobre o método ontológico-genético em Lukács. Gênese, processualidade histórica e mediação são conceitos centrais nesse método. Para Lukács, o processo de conhecimento só é verdadeiro quando ele busca a gênese dos fenômenos estudados, ao mesmo tempo, que procura explicar as transformações que ocorreram nesse objeto ao longo de sua existência histórica. Em outras palavras, quais mediações surgiram entre o aparecimento de determinado objeto e seu posterior desenvolvimento ao longo da história. Sucintamente, tal método tem como objetivo compreender o processo de gênese e complexificação de determinado objeto. Assim,

Também na consideração dessa questão devemos aplicar o mesmo método utilizado até agora: expor a estrutura originária que se constitui no ponto de partida para as formas superiores e, simultaneamente, tornar visíveis as diferenças qualitativas que, no curso do desenvolvimento social posterior, se apresentam de maneira espontaneamente inevitável e modificam a estrutura originária do fenômeno de modo necessário,

\footnotetext{
${ }^{1}$ Para uma discussão mais aprofundada sobre a relação entre essência e aparência em Lukács ver Lessa (2012), em especial o capítulo 2 , intitulado, A ontologia de Lukács.
} 
inclusive de maneira decisiva em algumas determinações importantes. (LUKÁCS, 2013, p. 137).

Pois, se a prioridade da totalidade na abordagem metodológica de Lukács é um fato evidente, e a centralidade desse conceito é algo contínuo no pensamento do referido autor desde sua obra de juventude História e consciência de classe $^{1}$, também é de suma importância o conceito de historicidade do ser, pois, dessa forma, se impõe igualmente à necessidade de uma abordagem genética.

Tal procedimento metodológico tem como objetivo acompanhar a processualidade de determinado objeto desde sua gênese histórica até suas transformações ocorridas ao longo do tempo, sempre tendo em vista a relação entre essência e aparência. Apenas se compreendendo a gênese do objeto e sua processualidade histórica, pois o ente em questão "é sempre uma totalidade dinâmica, uma unidade de complexidade e processualidade" (LUKÁCS, 2012, pg.304). Com efeito, só se pode falar em um conhecimento verdadeiro para Lukács e para o materialismo histórico quando se tem em vista esse duplo movimento. Segundo Marx, essa historicidade seria a característica revolucionária da dialética que se encontra no próprio Hegel.

Em sua forma mistificada, a dialética esteve em moda na Alemanha porque parece
glorificar o existente. Em sua figuração racional, ela constitui um escândalo e um horror
para a burguesia e seus porta-vozes doutrinários, uma vez que, na intelecção positiva do
existente, inclui, ao mesmo tempo, a intelecção de sua negação, de seu necessário
perecimento. Além disso, apreende toda forma desenvolvida no fluxo do movimento;
porque não se deixa intimidar por nada e é, por essência, crítica e revolucionária.
(MARX, 2013, p. 91)

Pensemos, por exemplo, na análise de Marx no que se refere à Acumulação Primitiva, haja vista a necessidade do capitalismo de saquear outras regiões do planeta, em especial a África e a América, para que ele se estabelecesse enquanto modo de produção predominante na Europa. É assim que se percebe a importância que o método genético tem para o materialismo histórico, pois a dialética busca reconstruir conceitualmente a gênese dos fenômenos, evidenciando o caráter histórico de toda forma ser e, consequentemente, apontando para a possibilidade de superação de todo ente natural ou histórico.

Então, o método ontológico-genético em Lukács buscar compreender as diferenças existentes entre as três esferas ontológicas bem como as especifidades destas e suas interrelações, buscando apreender o processo de transição de um nível ontológico mais simples para um nível ontológico mais complexo.

No capítulo dedicado ao Trabalho, o pensador húngaro busca analisar as transformações que o ser social experimenta desde o surgimento do trabalho ou o pôr teleológico primário - em

\footnotetext{
1 "Esta concepção da totalidade, que tanto afasta em aparência da realidade imediata e que constrói esta realidade de um modo aparente "não-científico" é, de facto, o único método que pode captar e reproduzir a realidade no plano do pensamento. A totalidade concreta é, pois, a categoria fundamental da realidade. (LUKÁCS, 1974, pgs. 24-5.).
} 
direção a uma incessante complexificação da vida social quando emerge o pôr teleológico secundário, ou os complexos da superestrutura, movimento esse que possibilita o aparecimento da ética, da moral, dos complexos ideológicos em geral, que apresentam uma autonomia relativa ao trabalho, mas que conserva ainda elementos que têm sua origem no ato de trabalho, especialmente o pôr teleológico. Dessa forma, esse método busca tanto compreender as diferentes mudanças ocorridas em níveis ontológicos distintos quanto às mudanças que ocorrem em uma esfera específica de ser.

Vejamos agora como Lukács interpreta o método da economia política em Marx, ou melhor, da crítica da economia política. Metodologicamente, Lukács nos aponta que desde sempre Marx propõe uma separação entre dois complexos, o do ser social, que tem sua existência independentemente do fato de ser conhecido corretamente ou não, e o processo metodológico de sua apreensão conceitual a mais adequada possível. Pensamento e ser são ontologicamente distintos, mas conservam sempre uma unidade dialética.

Como o objeto em questão refere-se ao ser social, e não a um objeto da natureza, a crítica da economia política de Marx versa sobre a relação imediata dada entre pesquisador e objeto, de modo que o distanciamento existente entre o pesquisador e o objeto existente nas ciências da natureza seria inexistente nas ciências humanas, trata-se de uma diferença metodológica fundamental entre as ciências naturais e as ciências humanas.

A ciência econômica partiria de representações reais e concretas - no caso a população. No entanto, Marx conclui que houve pouco avanço para o entendimento dessa realidade em particular, cuja razão reside no fato de que se partirmos do ponto de vista de uma totalidade imediatamente dada, o processo de conhecimento irá necessariamente desembocar em representações e não no conceito, no “concreto pensado". Nesse sentido, Marx critica as posturas adotadas pelos economistas clássicos como Adam Smith e David Ricardo.

O caminho de Marx, segundo Lukács, é o de utilizar-se de "abstrações isoladoras", que nada mais são do que um processo de mediação entre a realidade empírica e o conceito, e através dessas realizar uma "viagem de retorno" que irá desembocar novamente na população, mas com a diferença de que agora ela seria uma totalidade rica em determinações e relações, através da qual estaríamos diante do "concreto pensado". Pois, consoante a lógica do método dialético e da interpretação de Lukács, a objetividade do conhecimento na dialética é consequência da unidade entre empiria e reflexão.

Posto desta forma, deve-se ter em mente que é a própria legalidade do real que indica o caminho a ser seguido na construção dessas "abstrações isoladoras" sob o eminente risco de se cair em construções idealistas e, portanto, falsas. 
A clivagem entre a metodologia materialista e o modo de conceber o real pelo idealismo ocorre da seguinte forma: o processo de construção dessas "abstrações isoladoras" é extremamente necessário no processo cognoscitivo para que transcendêssemos uma representação da totalidade e dessa forma podermos chegar a um conceito de totalidade rica em determinações, em suma, através da mediação dessas "abstrações isoladoras" passaríamos da representação e chegaríamos ao conceito. Porém, esse movimento do pensamento não pode se confundir com a gênese do próprio real, pois é necessário ter em mente que o processo de construção do conhecimento no materialismo histórico é uma unidade entre objetividade e subjetividade. A consciência participa ativamente no processo cognitivo, mas, essa última análise sempre tem que estar com os pés fincados na própria realidade sob o risco de cair em um idealismo que caracteriza o pensamento de Hegel.

É claro, portanto, que o método da economia política, que Marx designa como "viagem de retorno", pressupõe uma cooperação entre o procedimento histórico (genético) e o procedimento abstrativo-sistematizante, os quais evidenciam as leis e as tendências. A inter-relação orgânica, e por isso fecunda, dessas duas vias do conhecimento, todavia, só é possível sobre a base de uma crítica ontológica permanente de todos os passos dados, já que ambos os métodos têm como finalidade compreender, de ângulos diversos, os mesmos complexos da realidade. (LUKÁCS, 2012, p. 306).

Dada à singularidade ontológica do ser social e da impossibilidade de se separar os processos sociais através de experimentos efetivos é que se compreende a importância metodológica dessas "abstrações isoladoras", pois através delas é possível estabelecer as relações existentes entre os diversos elementos que compõem essa totalidade e ao mesmo tempo tem-se a possibilidade de se afastar os elementos secundários que apenas atrapalhariam o processo de apreensão ideal da realidade. O papel ativo da consciência no processo cognitivo tem como um dos objetivos transformar aquilo que é multiverso na realidade empírica em um universo, afastando aquilo que é essencial do que é inessencial para os objetivos de determinada investigação.

\section{A GÊNESE DO CONHECIMENTO E SUA DIMENSÃO ONTO-PRÁTICA.}

Voltemos agora a nossa análise para um dos aspectos mais importantes da obra de Lukács, a saber, a gênese do conhecimento humano e seu caráter onto-prático. Para isso, é necessário analisarmos a forma como ele constrói o conceito de trabalbo tendo sempre como ponto de partida a teoria marxiana. Segundo o autor, o trabalho é central em sua abordagem 
teórica, pois o mesmo teria propiciado o "salto ontológico", ou seja, a passagem da mera animalidade para a socialidade.

Do ponto de vista metodológico, Lukács parte do método marxiano das duas vias. A primeira via é a da decomposição analítico-abstrativa desse novo complexo do ser, no caso o ser social, e a segunda via, por sua vez, constitui-se em avançar em direção ao complexo do ser social, que a partir de agora se torna rico em determinações e relações. Iremos nos focar apenas na primeira parte desse movimento metodológico, pois, caso contrário, nos afastaria ao escopo deste artigo.

Recuperando o fundamento ontológico do método em Lukács, lembraremos que todo estágio de um ente por mais simples que ele seja tem um "caráter de complexo" e, nesse sentido, o trabalho está contido em um complexo maior, isto é, o complexo do ser social, que se constitui da linguagem, da divisão do trabalho e da cooperação social. Sendo assim, seria possível questionar a Lukács qual a razão do trabalho ser o fundamento do ser social e não, por exemplo, a linguagem.

A resposta a essa pergunta aparentemente complexa é muito simples, pois o trabalho dentro da perspectiva marxiana é o intercâmbio entre o homem e a natureza, que visa à produção de valores de uso para o atendimento de necessidades humanas. Devemos nos atentar para o caráter de mediação que o trabalho apresenta no ser social e é, por esse motivo, que o trabalho é compreendido por Lukács e por Marx como o fundamento ontológico do ser social, o vir a ser do homem. Já a linguagem pressupõe o homem em uma socialidade já plena desprovido desse caráter de transição que o trabalho apresenta. Sendo assim,

A resposta, em termos ontológicos, é mais simples do que possa parecer à primeira vista: todas as outras categorias dessa forma de ser têm já, em essência, um caráter puramente social; suas propriedades e seus modos de operar somente se desdobram no ser social já constituído; quaisquer manifestações delas, ainda que sejam muito primitivas, pressupõem o salto como já acontecido. Somente o trabalho tem, como essência ontológica, um claro caráter de transição: ele é, essencialmente, uma interrelação entre homem (sociedade) e natureza, tanto inorgânica (ferramenta, matériaprima, objeto do trabalho etc.) como orgânica, inter-relação que pode figurar em pontos determinados da cadeia a que nos referimos, mas antes de tudo assinala a transição, no homem que trabalha, do ser meramente biológico ao ser social. (LUKÁCS, 2013, p. 44).

Essa passagem da mera animalidade para o ser social não se deu através de uma progressão simples e retilínea, visto que se tratou de um salto ontológico. E, por se tratar se um salto, pressupõe uma ruptura com a então continuidade normal do ser precedente. Do ponto de vista da diferenciação do ser biológico para o ser social, residiria para Lukács o fato de que na esfera biológica não há nenhuma possibilidade imanente que leve os entes desta esfera ontológica para além de suas determinidades biológicas de adaptação ao meio ambiente. 
Diferentemente do que ocorre na esfera biológica, a sociedade humana tem a possibilidade de criar as suas próprias condições sociais de desenvolvimento sem que estas sejam uma resposta imediata aos instintos biológicos, às necessidades biológicas. Portanto, nas diversas formas de sociedade humana há um "recuo das barreiras naturais" nos dizeres de Marx. E é o próprio Marx que aponta essa clivagem ontológica que separa o ser social das esferas inorgânica e orgânica. Vale a pena relembrar, portanto, que não há uma independência do ser social em relação às outras duas esferas da realidade, pois se trata apenas de um recuo e não de uma superação por completo. Deste modo,

\begin{abstract}
Pressupomos o trabalho numa forma em que ele diz respeito unicamente ao homem. Uma aranha executa operações semelhantes às do tecelão, e uma abelha envergonha muitos arquitetos com a estrutura de sua colmeia. Porém, o que desde o início distingue o pior arquiteto da melhor abelha é o fato de que o primeiro tem a colmeia em sua mente antes de construí-la com a cera. No final do processo de trabalho, chega-se a um resultado que já estava presente na representação do trabalhador no início do processo, portanto, um resultado que já existia idealmente (grifo nosso). Isso não significa que ele se limite a uma alteração da forma do elemento natural; ele realiza neste último, ao mesmo tempo, seu objetivo, que ele sabe que determina, como lei, o tipo e o modo de sua atividade e ao qual ele tem que subordinar sua vontade. (MARX, 2013, p. 255-6).
\end{abstract}

Marx nesse trecho enuncia aquilo que é a categoria ontológica central do trabalho no caso o pôr teleológico ou prévia-ideação. É através dessa teleologia que o homem pode de forma consciente transformar a natureza produzindo as chamadas objetividades postas. E, como consequência dessa teleologia, nascida a partir do trabalho, que ele se torna o modelo de toda a práxis social independentemente das complexas mediações que vão surgindo ao longo do desenvolvimento histórico, pois toda ação social pressupõe uma finalidade e uma escolha entre distintas alternativas.

Para se evitar possíveis equívocos com essa interpretação luckasiana acerca do trabalho, Lukács, de forma alguma tende a identificar todas as formas de objetivações humanas, como o direito, a política como diferentes formas de trabalho. Ele analisa o trabalho enquanto protoforma de toda práxis social, e, ao mesmo tempo, em sua análise não há nenhum vestígio de juízo de valor por parte dele no que se refere a essa categoria. Segundo ele, seriam às determinações que existem na própria realidade efetiva.

Haveria, dessa forma, uma prioridade ontológica do trabalho quando comparado com outras objetivações humanas, ou seja, o trabalho não teria um valor maior do que a arte, por exemplo, explicando melhor o trabalho e a arte, dentro dessa perspectiva, a arte é tão importante quanto o trabalho para a formação omnilateral do ser humano. Então, se o trabalho tem essa prioridade ontológica isso significa que sem o trabalho não poderia ter surgido a humanidade. Como exemplos poderiam citar a prioridade ontológica do ser sobre a consciência, pois existe ser 
sem consciência, mas não há possibilidade de existir consciência sem o ser. Essa é a lógica da interpretação de Lukács.

Analisemos agora a lógica imanente do trabalho e sua relação com o conhecimento humano e com o surgimento da ciência. Temos dois momentos distintos no ato de trabalho para Lukács: o já mencionado pôr teleológico e a causalidade. Salientemos que o ato do pôr teleológico não significa em Lukács um mero elevar-se à consciência, ou um mero processo cognitivo. $\mathrm{O}$ pôr teleológico do trabalho desencadeia um processo real e, portanto, apresenta um caráter ontológico. Ele, nesse sentido, busca acentuar o caráter ativo da consciência humana.

O segundo momento do trabalho é o da apreensão dos nexos causais que operam à realidade objetiva. $\mathrm{O}$ ato de trabalho necessariamente impõe que sejam conhecidos de forma exata os nexos causais que operam na realidade, pois caso a apreensão desses nexos não ocorra de forma correta pela consciência não se terá o produto do trabalho e a consequência será o fracasso de uma determinada ação humana.

Sendo assim, a causalidade em Lukács é um princípio de automovimento da própria realidade. Ele ressalta o fato de que mesmo o trabalbo possibilita que se fizesse um rearranjo desses nexos causais. Devemos nos atentar para esse rearranjo, pois não se trata de uma mudança da legalidade que existe na própria natureza - mesmo às mudanças que o ato de trabalho impõe nos objetos naturais-, não são capazes de produzir no limite uma transformação da natureza dos entes necessários para a produção dos valores de uso. Portanto, o ato de trabalho não muda a natureza dos objetos, apenas possibilita a transformação deles tendo como objetivo a satisfação de necessidades humanas.

Dessa forma, o ato de trabalho possibilita que determinadas características sejam direcionadas de uma forma posta, e que no livre curso da natureza seria impossível o aparecimento de um objeto que foi talhado pelo trabalho.

Destarte, o ato teleológico necessita de uma consciência ativa que o ponha e a causalidade seria o movimento que repousa em si mesmo, legalidade essa intrínseca aos objetos. Se na teleologia há a necessidade de se existir uma consciência à causalidade prescinde dela. $\mathrm{O}$ trabalho possibilita a existência de uma unidade entre essas duas categorias que tomadas separadamente e de forma abstrata seriam heterogêneas. O pôr e o fim são igualmente necessários para que o ato de trabalho tenha sucesso. Porém, é a finalidade é que irá direcionar o processo cognitivo do ato de trabalho. 
seria impossível se ele não fosse precedido de tal pôr, que determina o processo em todas as suas etapas. (LUKÁCS, 2013, pg. 51).

Assim sendo, o ato teleológico divide-se em duas partes, o próprio pôr do fim e as investigações dos meios mais adequados para a consecução desse objetivo. Essa subdivisão é muito importante para a análise deste autor, pois o processo investigativo ou cognitivo tem uma dupla função para o ato de trabalho. A primeira função é a de pôr em evidência o em si dos objetos ou aquilo que governa seus movimentos e a segunda função é a de descobrir novas conexões, novas possibilidades que permitam que a finalidade posta obtenha sucesso. Então, essa dupla função do ato teleológico pressupõe um exato conhecimento da realidade objetiva e não uma mera representação dela.

Assim, se é o ato teleológico que direciona o conhecimento humano ou aquilo que se deve conhecer posteriormente a esse fundamental momento, a consciência humana deve buscar controlar qualquer influência subjetiva, quer sejam valores, emoções, instintos, para que tenha sucesso esse ato laborativo.

É por causa desse domínio de si mesmo que houve a possibilidade do homem tornar-se homem, dominar os instintos, os medos, as emoções em suas determinações biológicas é que permite a superação da mera animalidade. Essa é a importância do trabalho na hominização do homem, segundo Lukács.

Apontemos agora a relação entre o ato de trabalho e o surgimento da ciência. No processo de trabalho há uma necessidade de apreensão dos nexos causais dos objetos naturais, que seria uma consequência da investigação dos meios que mencionamos acima. Em suma, "[...] o ponto no qual o trabalho se liga ao surgimento do pensamento científico e ao seu desenvolvimento é, do ponto de vista da ontologia do ser social, exatamente aquele ponto por nós designados como investigação dos meios”. (LUKÁCS, 2013, p. 57).

A diferença fundamental entre os processos cognitivos que envolvem o ato laborativo e o pensamento científico se encontra na possibilidade que a ciência apresenta em transcender o conhecimento oriundo do trabalho, que se caracteriza pela sua particularidade, na direção de uma universalidade. A ciência para Lukács possibilitaria a superação do pensamento cotidiano, oriundo do trabalho, em sua heterogeneidade e fragmentação, em direção a um pensamento que se basearia na homogeneidade e na totalidade.

\section{Considerações Finais}


No presente artigo tentamos analisar alguns aspectos da reinterpretação da teoria social de Marx levado a cabo pelo pensador húngaro György Lukács. Nessa nossa análise, buscamos compreender alguns elementos centrais dessa discussão ontológica de Lukács tentando realizar uma articulação entre ontologia, metodologia e epistemologia.

Apontamos que há elementos na própria teorização de Marx e Engels que apontam fortemente para uma visão ontológica da realidade e que dessa forma essa releitura de Lukács nos parece muito importante para reencontrarmos o caráter extremamente revolucionário da teoria crítica de Marx. Assim como, mesmo indiretamente, a Ontologia do ser social de Lukács nos possibilita ter um importante arcabouço teórico para que realizemos um debate crítico com algumas teorizações então predominantes nas Ciências Sociais como, por exemplo, o pósmodernismo e o pós-estruturalismo. Com efeito, recupera-se a importância do conceito de trabalho, cuja relevância para a construção de uma teoria crítica deve apontar as distopias que vivenciamos em nossa realidade hodierna.

\section{REFERÊNCIAS:}

CHASIN, José. Marx - Estatuto Ontológico e Resolução Metodológica. São Paulo: Boitempo Editorial, 2009.

LESSA, Sérgio. Lukács: Método e Ontologia. In: Cadernos de Serviço Social. Recife: v.11, pp. 132-153, 1995.

- Lukács: Ontologia e Método: Em Busca de um Pesquisador(a) Interessado(a). In: Revista Praia Vermelha. Rio de Janeiro: v.1, n.2, 1999, pp. 141-173.

Lukács: Momento Predominante e Transição ao Comunismo. In: Revista Novos

Temas. São Paulo, Número 05/06, 2011-12. Disponível em: < http://www.sergiolessa.com/files/MomtPredo enviado.pdf> Acesso em: 23 Jan. 2015.

. Mundo dos Homens: Trabalho e Ser Social. São Paulo: Instituto Lukács, 2012.

LUKÁCS, György.. História e Consciência de Classe. Porto: Publicação Escorpião, 1974.

. Prolegômenos Para uma Ontologia do Ser Social. São Paulo: Boitempo Editorial,

2010.

. Para Uma Ontologia do Ser Social I. São Paulo: Boitempo Editorial, 2012.

. Para Uma Ontologia do Ser Social II. São Paulo: Boitempo Editorial, 2013.

MARX, Karl; ENGELS, Friedrich. A Ideologia Slemã. São Paulo: Boitempo Editorial, 2007.

MARX, Karl. Grundrisse. São Paulo: Boitempo Editorial, 2011.

. O Capital livro I. São Paulo: Boitempo Editorial, 2013.

TERTULIAN, Nicolas. Sobre o Método Ontológico-Genético em Filosofia. Revista Perspectiva, Florianópolis, Volume 27, Número 2, Página 375-408, out.2010. Disponível em: $<$ https://periodicos.ufsc.br/index.php/perspectiva/article/view/2175-795X.2009v27n2p375>. Acesso em: $<19$ jan. 2015. 